\title{
TECHNOLOGY AND TRANSFORMATION IN COMMUNICATION
}

\author{
Dr. K. R. Subramanian ${ }^{1 *}$
}

*1 Professor of Management \& Senior Consultant - Operations, Credait.com

*Corresponding Author: -

\begin{abstract}
:-
Recent technological advancements have a drastic impact on the way individuals communicate. Many research findings suggest that technology has a negative effect on both the quality and quantity of face-to-face communication. Despite individuals' awareness of the decrease of face-to-face communication as a result of technology, more than $62 \%$ of individuals observed on University campuses continue to use mobile devices in the presence of all. In response to the overwhelming presence of face time while viewing TV, several families have decided to implement a ban on video games, computers or smart phones. Due to the rapid expansion of technology, many individuals fear that people may be too immersed in the digital world and not present in the real world. People are becoming more reliant on communicating with friends and family through mobile phones and are neglecting to engage personally. A majority of individuals feel that the quality of their conversations degraded in the presence of devices, and many individuals were bothered when friends or family used technical devices while spending time together. Communication and collaboration play a big role in digital transformation.
\end{abstract}

Key words: - Communication technologies, digital transformation, face-to-face communication, digital devices and engagement there of making people unavailable for face-to-face communication.

\section{(c) $(\$)$}




\section{INTRODUCTION}

Many studies have been conducted regarding effect on social interaction and face-to face communication since the rise of mobile telephones and social media usage in the late 2000s. With technology advancing at a rapid speed and human interaction changing just as quickly, it may be impossible to predict the future. However, everyone should be aware that human interaction as was once known may have already changed forever. Over the last few years there has been a lot of noise about digital transformation in the workplace. We have been informed that as the business world starts moving faster and becoming more global, 'digitization" is the only way to keep up. But what do we mean by digitization?

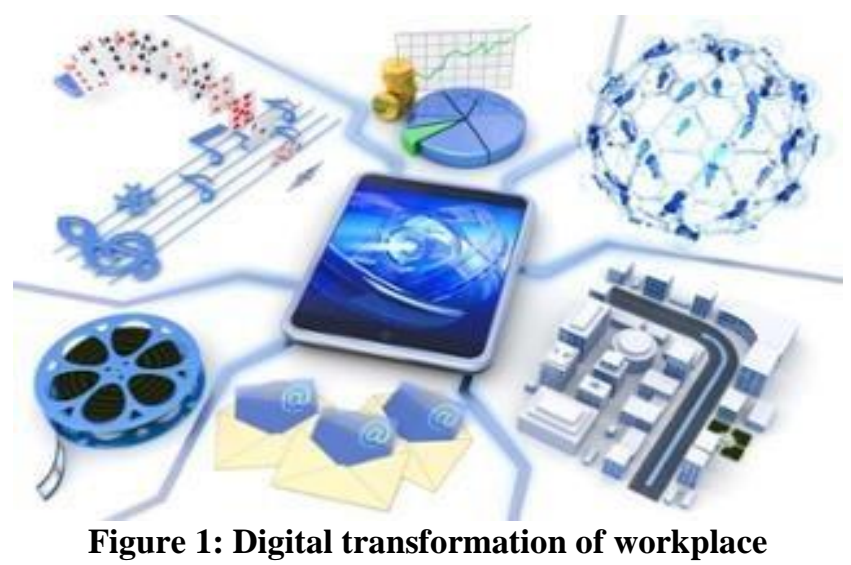

Digital transformation means many different things to different people. In general, we think of it as the transformation of business activities and processes to leverage digital technologies. But technology in itself is not the answer - to be meaningful, it is more of a way of doing things rather than the thing itself. There is no shortage of new digital technologies to invest in, from social, mobile, big data, cloud, Internet of Technologies, etc. Often the rush to fix a one-off problem results in a solution that is not integrated with the rest of the business infrastructure - including the employees themselves. The promise of a digital workplace that is more agile, productive and responsive is terrific, but to successfully transform it means a real focus on the human elements.

Employee engagement, user experience and adoption of the new tools make the difference between success and failure. One of the most important elements, if not THE most important element of a successful workplace, is effective communication. Using the right technology to transform the way employees and customers engage, interact and build relationships needs to be top of mind for all organizations. Workplace Communication and collaboration play a role in digital transformation.

Successful businesses are always on the lookout for current and future trends in technology. Studies show that employees are more satisfied and effective when they get to decide when, where, and how they work. Telecommuters and off-site freelancers are becoming ever more common, and people increasingly want to be able to work wherever they choose. Technology is the fuel that enables these trends to grow. Mobile devices, the cloud, collaborative software, and other advances allow for greater flexibility inside and outside of the physical office space.

Technology lets teams interact in new ways. The days of being limited by face-to-face meetings and impersonal conference calls are long over. Today's teams can work remotely, asynchronously, and across wide distances. They can use apps for file-sharing, real-time interaction, and communication management, to make collaboration as seamless as possible. Technology allows for the automation and streamlining of many operational processes and day- to-day tasks. While these changes certainly require adjustments, automation improves overall business efficiency. And at the individual level, automation can give workers the time to focus on other, more creative and thoughtful aspects of their jobs. Also at the individual level, work- related apps can help employees make the most of their time to get more done. Many companies are using technology in inspiring and innovative ways of using their office spaces. Technology networks can be used to understand individual preferences and encourage social networking in the workplace. Cisco is working on a system by which its workspaces could automatically adapt to the preferences of individual employees. While strategies like these may seem like something out of a sci-fi movie at the moment, they just might be the wave of the future.

\section{OBJECTIVES AND METHODOLOGY}

Today the workplace is no more a drag. We are all aware how communication plays a very important role in success of businesses today. Communication has been recognized as a key element for business success for a long time now; however the way people communicate today is different from what they used to do. Communication devices have changed and also the way people communicate with one another has changed. Face to face communication has become a thing of the past along with the introduction of telephones; but they have totally changed since the arrival of mobile and other technological changes and devices for personal communication. The objectives of the current research study is to evaluate the impact of technological changes in the way people communicate in the work place as well as personally. With this in mind the following specific objectives have been identified for the current research paper: 
1. Environment of business requiring change in communication styles.

2. Significant social factors affecting communication.

3. How organizations cope with this transformation

4. Employee attitudes to such changes.

5. Findings, Conclusion and recommendations.

As we have observed in the introductory remarks, digital transformation of the work place is impacting the way people interact and communicate with each other in an organizational as well as personal setting. Due to the fast pace of life, time is the premium commodity. Technology has given a lot of alternatives to people, on the way they communicate, collaborate and coordinate to get the work done. The present research paper is an attempt to find out what has changed and how organizations cope with such changes. Keeping in mind the above specific objectives a suitable methodology was to be identified to collect information, make suitable analysis and identify data suitable for further analysis and conclusion. During the process of survey of Literature it was found that a lot of work has been done in related areas and so the review produced excellent references for study and analysis. During this process adequate data was identified and obtained to complete the work of data analysis and arrive at conclusions. This has been done and results can be seen in the following pages.

\section{REVIEW OF LITERATURE}

Digital Transformation involves technology being introduced into the work culture to create efficiency through automation or skill reorientation, making the process more aligned with achieving a predetermined goal. As a whole, we are seeing our everyday lives and our workplaces becoming more and more digitized. From technological advancements such as the pervasiveness of smart phones, the prolific growth of the Internet of Things and even the super disruptive advent of machine learning and artificial intelligence, digital transformations are taking place every day. The latest trends in digitizing efforts are looking at how people work and connect with their employers and work environments.

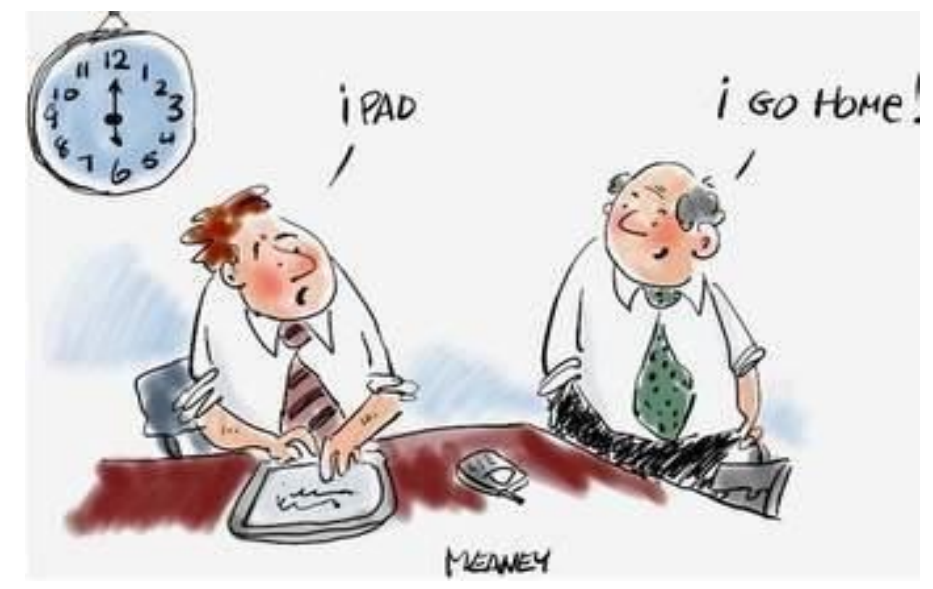

Figure 2: digital transformation

Introducing digital transformation has huge benefits for organizations-considering the workplace needs to keep pace with the changes the business environment. It is important for companies, now more than ever to respond appropriately through these challenges if they want to be successful. The rapid pace of technological change has been cited by most business leaders from Fortune 500 firms, as the single biggest challenge they face in today's world, according to a recent survey. So it's imperative that they commit to taking steps to counter this new wave of challenge if they want to keep their business moving forward towards success. When a company goes through a digital transformation, they miss out on their internal functionaries - mainly their employees. And, if the employees follow old practices, it would be difficult to build products and experiences that are in tune to today's consumer demands. 


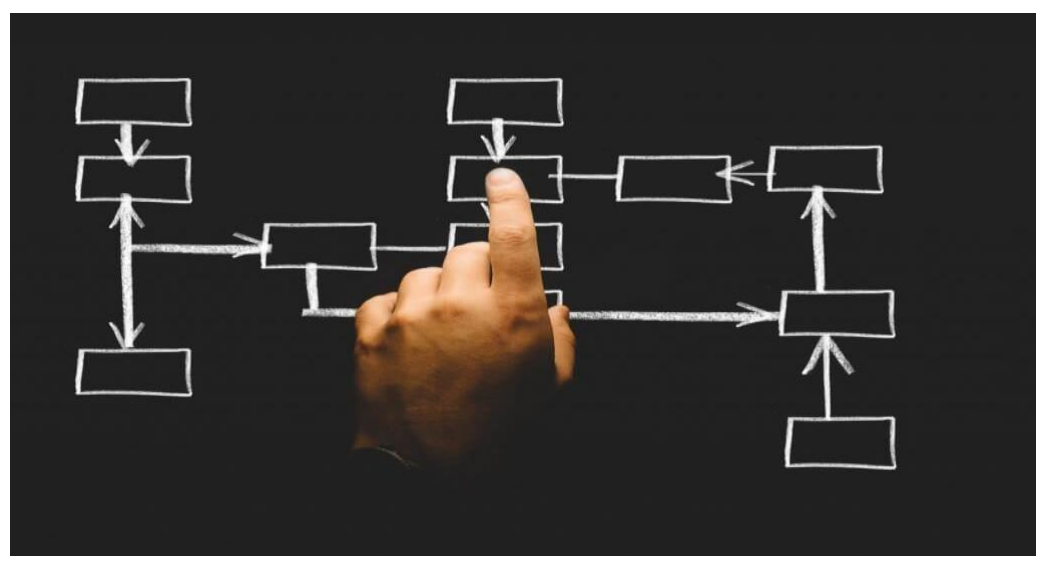

Fig. 3: Efforts to Bring Digital Transformation into the Workplace

Social Pulse is a tool which allows the management to know the prevalent collective emotions among its employees and it flags out the most prominent ones, like the dislike for the curved model among a majority of the employees. The result is a happier workforce that knows its voice is being heard at the very top. Like the famous Hawthorne experiment showed that employees' performance increases when they see that their employer is taking an interest in their activities, the attitudes haven't changed a lot. Technology might be the new way to signify interest, but when you are well connected to your employees, success becomes more achievable. Digital Transformation used to make the product experience better for clients revolves around bringing more engagement by taking the conversation with an individual on a more personal level. With employees, the steps towards transformation really are no different.

Workplace tools have a very strong influence on employee's motivation, performance and productivity. The right communications system can strengthen human connections over time and distance, and create an environment that is far more responsible and agile than ever before.

- New cloud-based "Unified Communications and Collaboration" solutions are key to enabling the digital workplace and flexible work lifestyles

- Employees can log in from anywhere on any digital device, and the system will immediately recognize them, their teams and all their contacts

- Presence capabilities let users find colleagues quickly and immediately begin messaging to share real- time information

- If the users need deeper collaboration, they simply click on the audio or video button to begin an audio or face-to-face call

- Screen sharing is also available for document sharing and updating, as well as sending files - all right from the same application

- Downloadable mobile apps mean that your smart phone (personal or otherwise) essentially puts your desk phone to rest.

- The business itself benefits from lower costs, more flexibility and higher reliability than is typically available from the new IP-based networks, providing faster speeds and better quality.

Technology is widely misconstrued as the only amicable solution to our problems in the workplace, but if you are going to bring in new HR technology, you need to make sure that the technology prioritizes the individual, and not the other way round. The individual needs to be at the center of all conversations to build a better workplace as it pays more dividends. The productivity levels of those organizations who manage to engage their employees more rise up by $22 \%$, compared to those who don't, according to a survey by Gallup.

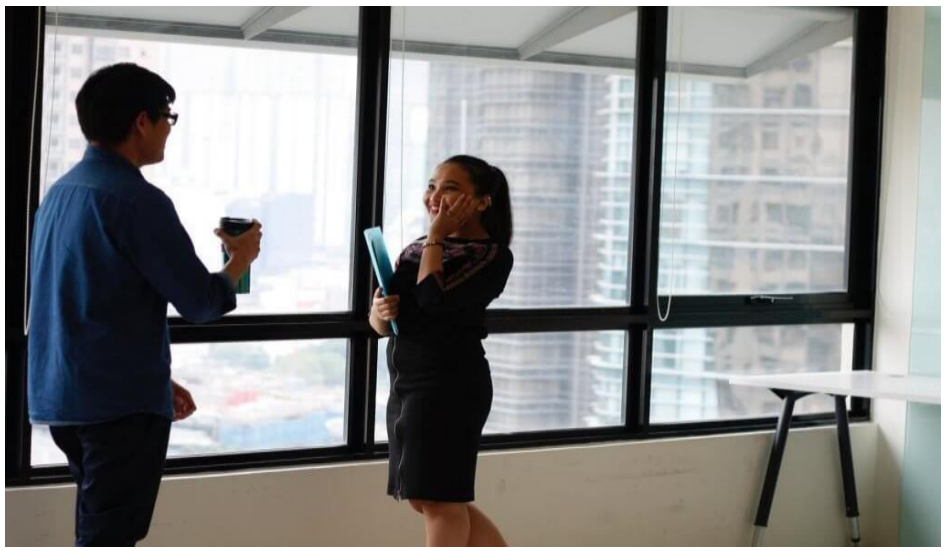

Figure 4: Powering richer inclusivity 
Implementing new HR technologies and believing that they will improve employee performance without initiating conversation with employees is a decision which is sure to end up as a disaster. Workforce would be directly affected by any new HR transformation you might bring in. A holistic strategy that fosters richer inclusivity can result in team cultures that will help businesses thrive in the future. The process of digitizing everything revolves around creating a strategic advantage that places you ahead of your competitors. Instead of eyeing bigger changes, you should think about bringing smaller improvements in structure, design, and policy on how you move about doing things. Technology is an integral part of our lives as we interact with it on so many different levels, be it using Uber to get home, Face book to check out your friend's photos from his latest vacation, WhatsApp to communicate with a client, or Google to search for the answer to anything and more. It is not surprising that technology can make our lives easier and put the resources to much better use.

Digital transformation in the workplace, led by HR technologies, should also work on the same lines, allowing each employee to feel that the new tool or change, improved his/her performance significantly and allowed him/her to play a visible part in the achievement of the strategic goals of the organization. The implications of such a massive digital transformation could be huge in the workplaces, given only that, the employees are prioritized when choosing, implementing and positioning them. In today's highly competitive environment, the biggest strategic asset, with which you can gain an edge above the rest, is your team. So Companies move forward, engage employees, and invest in them to build an organization that pushes ahead towards success.

Technology is now the most important communication aid for organizations. Technology has transformed how organizations conduct public relations and marketing, including how they interact with the media and stakeholders. The rapid development and adoption of new technology has changed the face of communication from traditional media. The technology revolution has dramatically altered marketing as well. Companies can no longer rely on traditional advertising to generate revenue. This trend has resulted in a number of developments in marketing communication: The growing abundance of technological devices means that virtually every person in the company has a computer at home and a mobile phone in their pockets. It is also commonplace for employees to bring their mobile devices (BYOD Bring Your Own Device) to work or to conduct work off of them from their home...Communication technology can be a blessing and a curse for businesses. Technology improves productivity, but it also complicates marketing strategies and public relations, as well as internal communications.

In the present global economy Technology allows us to easily connect with people worldwide using their own choice of forums. We don't have to wait for a stamped letter to make its way across the miles or rack up a big long-distance phone bill (as was the case not that long ago); instead via the Internet we can instantly reach almost anyone whether through email, instant message, social media, or countless apps. As the speed of communicating has gone up, costs have been dramatically reduced.

Information overload is becoming a reality, with the Internet providing much more knowledge at the click of a mouse than could even be imagined in the past. This means there is much more data that can be communicated about any topic than was previously possible, limited only by our own ability to find, absorb, and store this information. As a result, savvy communicators have learned to turn toward specific technology solutions to help them harness, organize, and manage the data deluge. The Spreadsheets app from the multi-platform office solution WPS Office, for example, allows users to more efficiently contain and categorize different types of data using commonly used formulas. The app offers built-in tables and cell styles that simplify data organization and presentation.

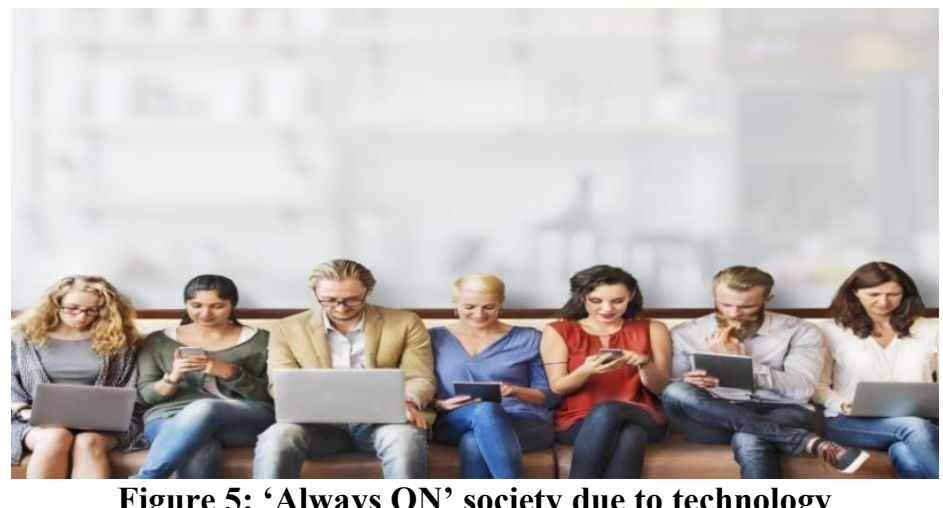

Figure 5: 'Always ON' society due to technology

The nature of communication has changed along with its increase in speed and volume. Mobile devices that fit in our pockets have tiny keyboards that make expedient communication desirable; hence an increase in the use of shortcuts, symbols, abbreviations, and new words that get the point across with fewer characters. A multiplicity of devices has also made communication fast like smart phone, laptop, tablet, or desktop. The tools give teams access to each other's edits and comments on the same document or spreadsheet, facilitating communication and collaboration toward common goals. While technology is often seen as the culprit behind a decline in face-to-face talking, we have to give credit to technology 
for opening up many new avenues for expanding the comparatively limited communication options we had available in the past.

For many of us, communicating with family used to mean sending letters and cards through the mail and getting no response until weeks lat er and pay phones were the only option to call home if our car broke down on the side of the road, or if we had to stay after school. For the past decade or so, technology has transformed the way we communicate, to some extent due to the advent of the Internet. Instead of mailing letters, we are writing e-mails through Gmail or Hotmail that can be sent instantaneously to a recipient. We can even add multiple recipients to these e-mails, so that more than one person can read them. Even more, we can send greeting cards- No postage needed! Mobile phones have become a godsend, letting us place calls no matter where we are-on the way to work, at the beach, at school, etc.

It's true that technology has also made society somewhat impersonal. As a result, it's difficult to tell when a person is serious or sarcastic-our clever turns of phrase can easily be misconstrued. Technology tends to make communication and it's quicker to just get out of your seat and walk to the person, or simply pick up the phone. Even worse, younger generations have forgotten how to spell and write complete sentences due to the increased use of text messaging on mobile phones. The State Examination Commission out of Dublin, Ireland said in a report that in many cases, teenagers seemed "unduly reliant on short sentences, simple tenses, and a limited vocabulary" and that with the use of phonetic spelling and little or no punctuation; it's beginning to pose a threat to traditional writing, not to mention oral communication. In addition, we've seen how addicted people can become to their smart phones, like the Apple I-Phone and the BlackBerry Storm 9530. (You've probably heard the term for it: "Crack Berry.") People possess an obsessive need to constantly check their e-mail, even when on vacation with the family. It's as if we're afraid we'll miss something important or be out of the loop.

Twenty-first century communication has changed how we perceive the world in three essential ways: connectivity, authenticity, and style. The first way is obvious to any sentient being, but has transformed politics, business, and culture, bringing about the upheaval of within reach of the digital world. The digital era has radically flattened hierarchies of communication everywhere, and completely reshaped the old power relationship between the rulers and the masses. Now, a single furious customer can bring down a restaurant, a single, impassioned person can ignite support for a cause, and a single disgruntled citizen can start a movement and bring down a government. This shift has two implications for communications. First, it necessarily increases the volume and consequently brings down the accuracy and appropriateness of the information flow. Second, anyone's voice can get heard, and perhaps even get the hearing it deserves. That's the good news. You're competing with phony news, but if you persist, your story will most likely be heard.

\section{DATA ANALYSIS AND CONCLUSION}

As a big source of information, education, communication and entertainment, social media is going to be next big challenge for the different aspects of our social and personal Communication. Social media is creating a new kind of social order; it is strengthening social network but weakening inter-personal relations. User-generated content will lead to a new form of addiction for younger generation (difficult to rehabilitate), an age of over communication (24 hrs messaging and chat) and alienation on the other hand (leading to psychological disorder). Technology is everywhere; it has changed every aspect of our lives, the way we buy our books, listen to our favorite music, book our holidays, even the way we stay in touch with family and friends; it rules everything and most importantly how and why we communicate. Technology has revolutionized our daily routines but if there is one thing that has really evolved beyond recognition that would be the way we work.

Significant social factors would include the demographics of the new generation of working people in organizations (mostly young and educated). This set is digitally competitive and they know their way about. Their Communication style and language are unique. They want to be brief and communicate through texting and e-mails and are up to date with their information since they belong to the "always on" social group. Their opinions are shaped through peer pressure and not necessarily through data analysis or verification. So, this opens up the gate for communication and contact through the web and electronic media mostly mobile devices.

Organizations cope with these transformations by avoiding traditional media for publicity and customer contact. They identify opinion leaders whom they influence through web media for hosting favorable opinions and review of their products and services. Their recruitment is aimed at Talent identification, Recruitment and Training to be savvy with new media. As already pointed out in the review of Literature, the work arrangements are flexible and employees are facilitated to work at convenient hours and places, because the new digital media allows them to be in touch with their colleagues at all times.

The prospective employees like such flexible arrangements so that they can pursue their personal hobbies by creating spare time for leisure activities. This keeps them motivated. This is a big challenge of the current Human Resources Managers to identify and recruit such talent. Conventional forms of recruitment and placement have been replaced by Talent identification and access through the digital connective devices. The author would like to conclude by saying it is a "survival of the fittest" era. The prospective candidates for recruitment, placement and promotion go through Training and retraining to continuously update their skills and Talent. 


\section{SUGGESTIONS AND RECOMMENDATION}

Complex technology is now widely available and popular, with new developments emerging almost every day. So how companies keep up with and make sense of technological changes behind media and communication systems, changing social perceptions, and new media products of social forces will determine their success. While these new media are displacing long-established business models and corporate strategies, they also provide new and exciting opportunities for companies to improve customer relationships and expand businesses through strategies that adapt to this constantly changing new media era.

There is plenty of evidence demonstrating the power of digital communications and new media. Most marketers have the first-hand experience of the diminishing returns from traditional techniques. This is why many organizations seem to be waiting for the digital revolution to come through because they know intellectually it will impact them perhaps tomorrow, not today. A day which never seems to arrive; until it's too late. By then their competitor has seized the initiative and dominated them or until they get the wake-up call that their competitor is first in search, has higher and more qualified web traffic, gets better conversions, which lead to improved sales, lower costs and higher margins.

These facts confirm how overwhelmingly important technology has become not only for us but also for businesses. Should organizations ignore what's happening out there and continue "business as usual"? This would be a terrible mistake; organizations have to create a new type of structure, one that is social and spreads across all functions. Only if organizations embrace the social media and technology revolution, will they be able to grow and move forward.

\section{BIBLIOGRAPHY}

\section{A. PRINT \& PUBLICATIONS}

[1]. Ahlqvist, Toni, Bäck, A., Halonen, M., Heinonen, S. (2008). Social media road maps exploring the futures triggered by social media. VTT Tiedotteita - Valtion Teknillinen Tutkimuskeskus (2454): 13.

[2]. Brignall, T.W., \& van Valey, T. (2005). The impact of Internet communications on social interaction. Sociological Spectrum, 335-348.

[3]. Berker, T., Hartmann, M., Punie, Y. and Ward, K. (eds) (2006) Domestication of Media and Technologies, Open University Press, Maidenhead

[4]. Buckingham, D. (2008) Youth, Identity, and Digital Media. The John D. and Catherine

T. MacArthur Foundation Series on Digital Media and Learning. Cambridge, MA: The MIT Press.

[5]. Buse, C. (2009) 'When You Retire, does Everything become Leisure? Information and Communication Technology Use and the Work/Leisure Boundary in Retirement', New Media and Society, Vol.11, No.7, pp.1143-61.

[6]. Campbell, S.W., \& Kwak, N. (2011). Mobile communication and civil society: Linking patterns and places of use to engagement with others in public. Human Communication Research, 37, 207-222

[7].Caron, A. (2000) New Communication Technologies in the Home: A Qualitative Study of the Introduction, Appropriation and Uses of Media in the Family, Young People and the Media, Sydney: International Forum of Researchers

[8].English-Lueck, J. (1998) Technology and Social Change: The Effects on Family and Community, COSSA Congressional Seminar, 19th June.

[9]. Fortunati, L. (2009) 'Old and New Media, Old Emotion', in Vincent, J. and Fortunati, L. (2009) Electronic Emotion. The Mediation of Emotion via Information and Communication Technologies, Peter Lang, Oxford, pp.35-62.

[10]. Feeny, D. and Willcocks, L.P. (1998). Core IS Capabilities for Exploiting Information Technology. Sloan Management Review. 39(3) pp 9-21

[11]. Fortunati, L. and Manganelli, A. (2004) The Family, Communications and New Technology, Proceedings of the Conference 'Mobile Communication and Social Change, October 18-19, Seoul, Korea.

[12]. Gilligan, R. (2004) 'Understanding Material Culture and Digital Media: A Case Study of Cultural Factors Shaping Rural Adoption and Use of ICTs', in Haddon, (Ed.) International Collaborative Research. Cross-Cultural Differences and Cultures of Research, COST, Brussels, pp.51-86.

[13]. Misra, S., Cheng, L., Genevie, J., \& Yuan, M. (2014). The iphone effect: The quality of in-person social interactions in the presence of mobile device. Environment \& Behavior, 1-24.

[14]. Przybylski, A.K., \& Weinstein, N. (2012). Can you connect with me now? How the presence of mobile communication technology influences face-to-face conversation quality. Journal of Social and Personal Relationships, 1-10.

[15]. Rideout, V.J., Foeher, U.G., \& Roberts, D.F. (2010). Generation M2: Media in the lives of 8- to- 18 year olds. Kaiser Family Foundation, 1-85.

[16]. Turkle, S. (2012). Alone together: Why we expect more from technology and less from each other. New York, NY: Basic Books

[17]. Kaul V (2012) The Changing World of Media \& Communication. Journal of Mass Communication and Journalism 2:116. doi:10.4172/2165-7912.1000116

[18]. Haddon, L. and Silverstone, R. (1994) 'The Careers of Information and Communication Technologies in the Home', in Bjerg, K. and Borreby, K. (eds.) Proceedings of the International Working Conference on Home Oriented Informatics, Telematics and Automation, Copenhagen, 27th Jun- 1st July.

[19]. Hemer O, Thomas T (edn.) (2005) Media and Glocal Change: Rethinking Communication for Development. Clacso 
/Nordicom: Buenos Aires/Gothenburg.

[20]. Kaplan Andreas M., Haenlein Michael. (2010). Users of the world, unite! The challenges and opportunities of social media, Business Horizons, Vol. 53, Issue 1 (page 61)

[21]. Kietzmann, H., Jan, Hermkens, Kristopher. (2011). Social media? Get serious! Understanding the functional building blocks of social media. Business Horizons Vol54: 241-251.

[22]. Lim, S. S. (2009) Young People and the Digital Divide - An Ethnographic Study of Media-have-less Youths. Keywords in Communication: 2009 Annual Conference of the International Communication

[23]. Lugano, G. and Peltonen, P. (2012) 'Building intergenerational bridges between digital natives and digital immigrants: Attitudes, motivations and appreciation for old and new media in Finland', in Loos, E., Haddon, L. and Mante-Meijer, E. (eds)(2012) Generational Use of New Media, Ashgate. Aldershot, 151-170./

[24]. Mascheroni, G., Pasquali, F., Scifo, B., Sfardini, A., Stefanelli, M. And Vittadini, N. (2011) 'Young Italians' crossmedia cultures', in Haddon, L. (Ed.) The Contemporary Internet: National and Cross-National European Studies, Peter Lang, Frankfurt, pp. 33- 54.

[25]. Nurmela, J. (2003) 'A "Great Migration to the Information Society?" Patterns of ICT Diffusion in Finland in 19962002', in Haddon, L., Mante-Meijer, E., Sapio, B., Kommenon, K-H, Fortunati, L., and Kant, A. The Good, the Bad and the Irrelevant: The User and the Future of Information and Communication Technologies, Conference Proceedings, 1st-3rd, September, Helsinki.

[26]. Pathak-Shelat, M. and DeShano, C. (2014) 'Digital youth cultures in small town and rural Gujarat, India', New Media \& Society, Vol. 16(6) 983-1001

[27]. Raban, Y and Brynin, M. (2006) 'Older People and New technologies', in Kraut, R, Brynin, M. and Kiesler, S. (2006) Computers, Phones and the Internet. Domesticating Information Technology, Oxford University Press, Oxford, pp.43-50.

[28]. Robinson, J. and de Haan, J. (2006) 'Information Technology and Family Time Displacement', in Kraut, R, Brynin, M. and Kiesler, S. (2006) Computers, Phones and the Internet. Domesticating Information Technology, Oxford University Press, Oxford, pp.70-83.

[29]. Sefton-Green, J. (2006) 'Youth, Technology, and Media Cultures', Review of Research in Education, 30, pp.279306.

[30]. Selwyn N (2003) 'Apart from Technology: Understanding Peoples' Non-use of Information and Communication Technologies in Everyday Life', Technology in Society 25(1): 99-116.

[31]. Tabernero,C., Sánchez-Navarro, J. And Tubella, I. (2008) 'The Young and the Internet: Revolution at Home. When the Household becomes the Foundation of Socio-Cultural Change', Observatorio, Vol 2, No 3, pp.273-91.

[32]. Turk, T., Sapio, B. and Palombini, I. (2008) 'The Adoption of Terrestrial Digital TV: Technology Push, Political Will or Users' Choice? n Loos, E., Haddon, L. and Mante- Meijer, E. (eds) The Social Dynamics of information and Communication Technology, Ashgate, Aldershot, pp.29-54.

[33]. Vershinskaya, O. (2003) 'Russian Youth and ICT', in Haddon, L., Mante-Meijer, E., Sapio, B., Kommenon, K-H, Fortunati, L., and Kant, A. (eds) The Good, the Bad and the Irrelevant: The User and the Future of Information and Communication Technologies, Conference Proceedings, 1-3, September, Helsinki.

[34]. Weber (H) (2005) 'Portable Pleasures. Mobile Lifestyles with Portable Electronics, in Pantzar, M. and Shove, E. (eds) Manufacturing Leisure: Innovations in Happiness, Well- being and Fun (Part II) National Consumer Research Centre, Helsinki, Finland, pp. 134- 59

\section{B. WEB REFERENCES}

1. http://www.wbur.org/2013/01/17/digital-lives-i

2. http://www.eater.com/2013/8/1/6392735/la-restaurant-bans-cell-phones-to-prevent- gastro-add

3. http://www.theatlantic.com/technology/archive/2013/06/more-than-90-of-adult- americans-havecell-phones/276615/

4. http://www. census.gov/prod/2013pubs/p20-569.pdf

5. http://eprints.lse.ac.uk/66997/ 